LA-8311-PR

Progress Report
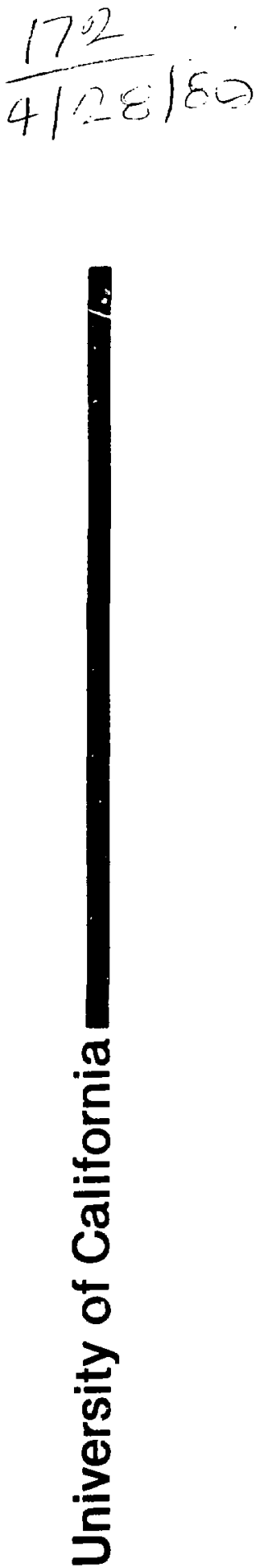

$\frac{0}{6}$

$\frac{2}{\frac{5}{5}}$
General-Purpose Heat Source Project and Space Nuclear Safety and Fuels Program

January 1980

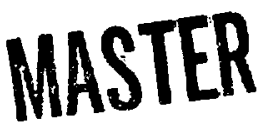




\section{General-Purpose Heat Source Project and Space Nuclear Safety and Fuels Program January 1980}

Compiled by

W. J. Maraman 
This formal monthly report covers the studies related to the use of $238 \mathrm{PuO}_{2}$ in radioisotopic power systems carried out for the Advancet Nuclear Systems and Projects Division of the Los Alamos Scientific Laboratory. The two programs involved are the followin:

General-Purpose Heat Source Development

Space Nuclear Safety and Fuels.

Most of the studies discussed here are of a continuing nature. Results and conclusions described may change as the work continues. Published reference to the results cited in this report should not be made without the explicit permission of the person in charge of the work. 
GENERAI_-PURPOSE HEAT SOURCE PROJECT AND

SPACE NUCLEAR SAFETY AND FUELS PROGRAM

JANUARY 1980

Compiled by

W. J. Maraman

I. GENERAL-PURPOSE HEAT SOURCE

\section{A. Management}

A. The current schedule for the remainder of the General-Purpose Heat Source (GPHS) project is given in Fig. $1-1$.

B. Design Iinpact Tests

No impact tests were carried out this month. Plans for the CECF insulation impact tests and the pyrolytic insulation impact tests were completed.

\begin{tabular}{|c|c|c|c|c|c|c|c|c|c|c|c|c|c|c|c|c|}
\hline \multirow{2}{*}{ PHASE/TASK } & \multicolumn{2}{|c|}{ FY79 } & \multicolumn{10}{|c|}{ FY80 } & \multicolumn{4}{|c|}{ FY81 } \\
\hline & Ji & $\mathrm{A} / \mathrm{S}$ & 0 & N] & & $J F$ & $\bar{M}$ & $A$ & M] & J]. & $\sqrt{A}$ & $\mathrm{~s}$ & $0]$ & V.D & $J$ & $\bar{F}$ \\
\hline REDESIGN & & & & & & & & & & & & & & & & \\
\hline IIIPACT TESTS & & & & & & & & & & & & & & & & \\
\hline$P G$ & & & & & & & $\Delta$ & & & & & & & & & \\
\hline CBCF & & & & & & $\angle$ & & & & & & & & & & \\
\hline VIBRATION TESTS (GE) & & & & & & & & & & & & & & & & 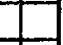 \\
\hline$P G$ & & & & & & 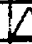 & & & & & & & & & & 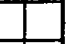 \\
\hline CBCF & & & & & & & $\bar{\triangle}$ & & & & & & & & & \\
\hline FINAL DESIGN DEFINUTION & & & & & & & & $\Delta$ & & & & & & & & \\
\hline & & & & & & & & & & & & & & & . & \\
\hline VERIEICATION & & & & & & & & & & & & & & & & \\
\hline AGIIIG (2) & & & & & & & & & & & 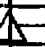 & & - & $E$ & $\theta$ & \\
\hline IMPACT (4) & & & & & & & & 7 & & $E$ & 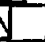 & & & & L & \\
\hline EXPLOSIOH (4) & & & & & & & & & & & A & & & & & \\
\hline FIRE & & & & & & & & & & 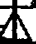 & & & & & & \\
\hline DYNAPIC IESI (GE) & & & & & & & & $\Delta$ & & & & & & & & \\
\hline & & & & & & & & & & & & & & & & \\
\hline PERFORMARCE ANIALYSIS REPORT & & & & & & & & & & & & 4 & 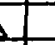 & & 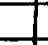 & \\
\hline & & & & & & & & & & & & & 1 & & & \\
\hline FINAL REVIEW & & & & & & & & & & & & & 4 & & 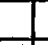 & \\
\hline & & & & & & & & & & & & & & & & \\
\hline & & & & & & & & & & & & & & & & \\
\hline
\end{tabular}

Fig. I- T.

GPHS Project Schedule. 


\section{Fuel Development}

The porosities of the edge and center of the Los Alamos Scientific Laboratory (LASL) fuel pellet from sample IRG-19 (GP 25) were determined to be 31.3 and $17.4 \%$, respectively, while the porosities in the comparable regions of the fuel from IRG-23 (GP 30) were found to be 18.7 and $12.2 \%$.

D. Clad Development

The accumulated exposure time of the $\mathrm{Pt}-3008$ vs $238 \mathrm{PuO}_{2}\left(1100^{\circ} \mathrm{C}\right.$, vacuum) was $123.7 \mathrm{~h}$ as of February 1, 1980.

\section{E. Graphite Properties}

1. Air Permeation Rate. A flow apparatus was constructued for measuring the permeation of air through the fine-weave, pierced fabric (FWPF) 3D graphite used in the GPHS program. A Wallace-Tiernan gauge was used to measure the differential pressure across the samples and the vacuum side was maintained at $1 \mathrm{~mm}$ with a forepump. The total void volume of the gas manifold was estimated to be $2035 \mathrm{~cm}^{3}$. The 50 -mm-diameter samples were glued into the holder, one with the Z-axis aligned parallel and other with it perpendicular to the direction of gas flow. A third sample had a standard-diameter aeroshell plug, with the Z-axis perpendicular to the air flow. The plain samples were $5 \mathrm{~mm}$ thick, while the closurs sample was $10 \mathrm{~mm}$ thick. Variations in the pressure and flow rate were measured as a function of time. The molecular flow rate $(\mathrm{dn} / \mathrm{dt})$ was calculated from the rate of pressure decrease by using the relationship:

$$
\mathrm{dP} / \mathrm{dt}(\mathrm{VA} / \mathrm{RT})=\mathrm{dn} / \mathrm{dt}=\mathrm{dV} / \mathrm{dt}(1 \mathrm{~atm} / \mathrm{RT}),
$$

where $d p / d t=$ rate of pressure decrease $(\mathrm{atm} / \mathrm{s})$,

$V=$ volume $\left(\mathrm{cm}^{3}\right)$

$\mathrm{A}=$ Avúgadro's number $\left(6.023 \times 10^{2.3} \mathrm{molecules} / \mathrm{mol}\right)$,

$\mathrm{R}=$ gas constant $\left(82.06 \mathrm{~cm}^{3} \mathrm{~atm} / \mathrm{K} / \mathrm{mol}\right)$,

$\mathrm{dn} / \mathrm{dt}=$ molecular flow rate (molecules $/ \mathrm{s})$,

$\mathrm{dV}^{\prime} / \mathrm{dt}=$ standard flow rate (sccs).

The results from this study are listed in Table I- 1 . The measured time, pressure, arid flow rate are listed aloirg with the calculated molecular flow. The case where the flow is parallel to the Z-zxis shows the highest flow rate at a given pressure, whereas the sample with the tireaded plug displayed a rate between the other samples. This observation is expected since ine former was a combination of the other two characteristic directions in the graphite. The flow rate is plotted as a function of the pressure in Fig. I-2 for the three samples. The diagram shows the significantly higher flow rates for the case of flow parallel to the Z-axis. The flow rate is plotted as a function of time in Fig. I-3 starting at the pressure of $300 \mathrm{~mm}$ for all three samples. If the thread root diameter is used to calculate the relative volumes of the two directions in the closure sample and the flow rates measured for the two solid samples, the calculated flow rate is in good agreement with the measured flow rate through the closure sample.

This study has shown that the FWPF 3D graphite does not appear to provide a major barrier to the flow of air into the interior of the GPHS module, especially in the case of the Z-axis parallel to the air flow direction and that the presence of the joint in the aeroshell has little or no effect on the total permeation rate. 
TABLE I-1

PRESSURE AND FLOW RATES OF AIR PERMEATION THROUGH FWPF FOR FLOW PERPENDICULAR AND PARALLEL TO Z-AXIS AND FOR A THREADED CLOSURE
Time
(sec)

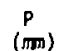

Alow Perpendicular to $Z$-axis

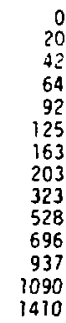

B. Flow Parallel to Z-axis

$\begin{array}{rr}0 & 300 \\ 31 & 200 \\ 59 & 150 \\ 100 & 100 \\ 120 & 80 \\ 160 & 60 \\ 184 & 50 \\ 215 & 40 \\ 255 & 30 \\ 312 & 20 \\ 428 & 10\end{array}$

760
700
550
600
550
500
450
400
300
200
150
100
80
50

0
13
37
75
130
172
229
215
445
485
530
580
640
717
815
950
1140
1495

Flow
(sccm) $\quad \begin{gathered}\text { log flow } \\ \text { (molecules/sec) }\end{gathered}$

20296

20.176

20.176

20.071

20.000

$19.93 \mathrm{~B}$

19.865

19.758

19.508

19293

19.136

18.936
18.791

20.328

20.328
20.071
19.905

19.819

$19.51 \mathrm{~B}$

19.439

19.328

19.217

19.063
18.75

18.755

20.550

20.550
20.439

20.439
20.372

20.079

19.895

19.895
19.762

19.762
19.584

19.404

19.217

19.166

19.120

19.041

18.933

8.828

18.689

18.540

18,269

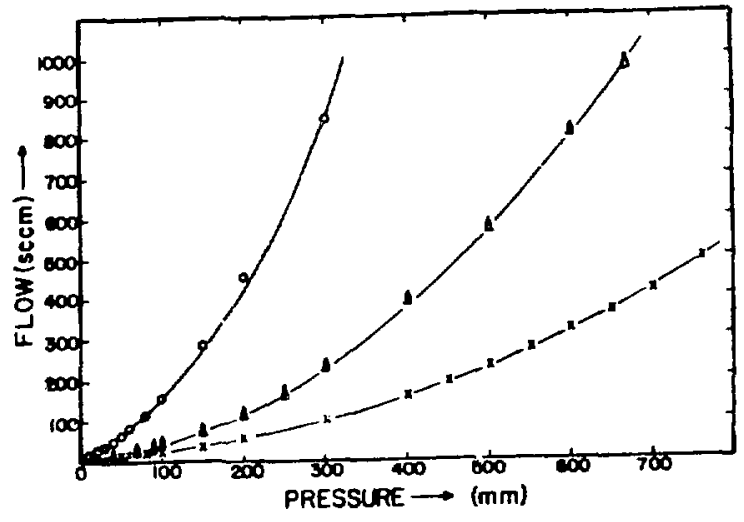

Fig. I -2 .

Pressire dependence of flow rate of air through FWPF graphite for flow parallel (o) and perpendicular ( $x$ ) to $Z$-axis and for threaded cap $(\Delta)$.

2. Lock-Member Shear Tests. Some concern was raised regarding the shear strength of the GPHS locking members when the $X$ and $Y$ fiber directions were oriented at $45^{\circ}$ to the shear loading direction. To determine this property, simulated shear tests were performed with the assembly shown in Fig. I-4. The locking plate was FWPF graphite with the $X-Y$ axes at $45^{\circ}$ to the loading $d i$ rection. The locking members were bulk graphite.

Two tests with double lock members were performed. In the first test, failure occurred at a load level of $4.54 \mathrm{KN}$ (1020 1bs) resulting in a failure stress of $31.6 \mathrm{MPa}$ (4580 psi) per lock member. For the second test, the failure load was $4.71 \mathrm{KN}$ (1060 1bs) and the failure stress was $32.8 \mathrm{MPa}(4760$ psi). The scatter in these two values

is probably a result of the statistical strength nature of brittle materials. In both tests, load-displacement curves were nonlinear, but lock member failure occurred in a brittle fastion.

Characteristics of failed lock members are shown in Fig. I-5. The lock members tended to fail by splitting down the mid-plane. The FWPF plate showed very little damage after test. In a previous test with the FWPF graphite $X$ and $Y$ axes at 0 and $90^{\circ}$ to the shear loading direction, the failure load was $4.35 \mathrm{KN}$ (979 1bs) with a stress per lock member of $30.3 \mathrm{MPa}$ ( $4400 \mathrm{psi}$ ). This comparison shows that FWPF $X-Y$ fiber orientation has virtually no effect on the shear of the locking members. 


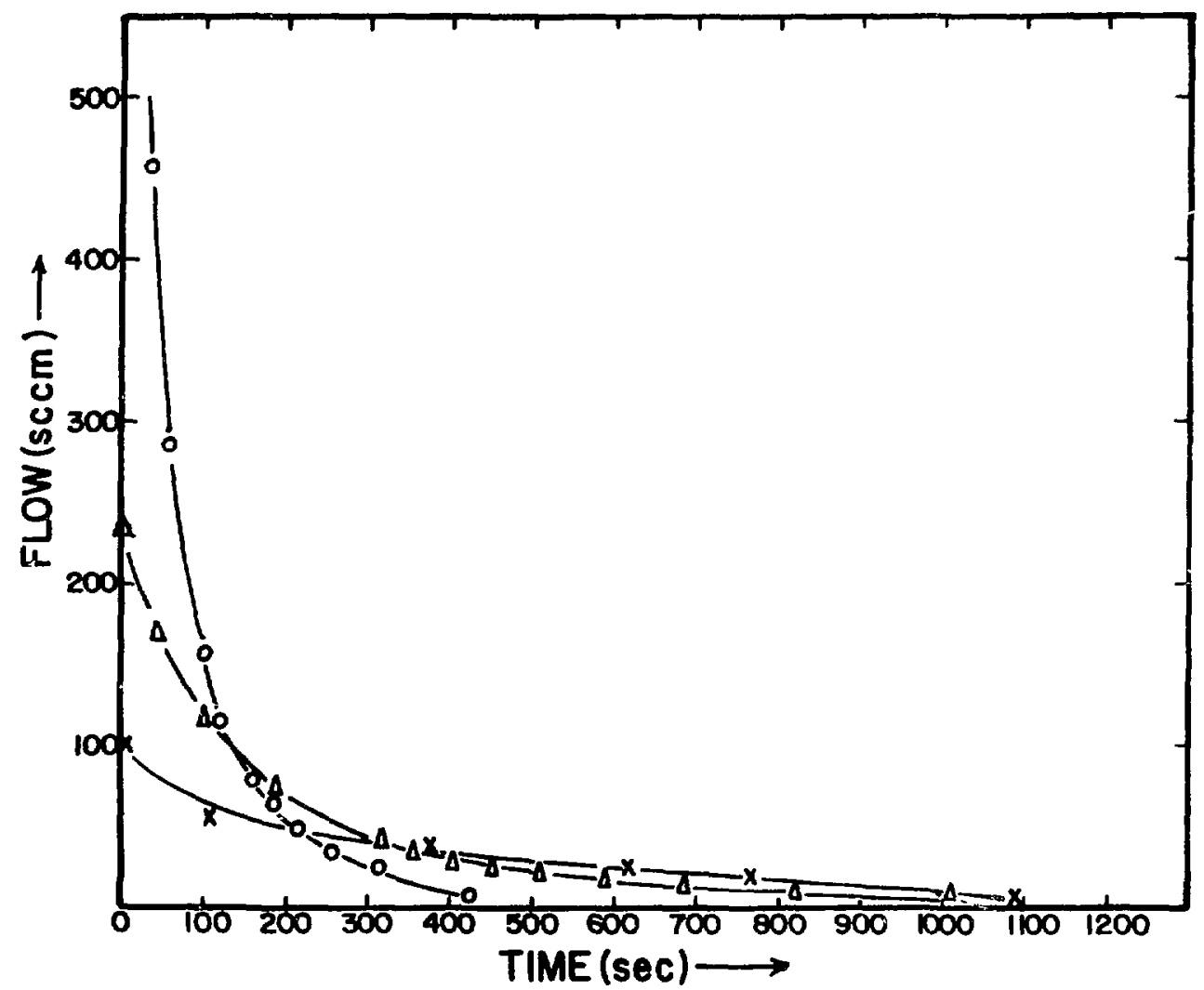

Fig. I-3.

Time dependence of air flow rate through FWPF araphite for flow barallel (n) and
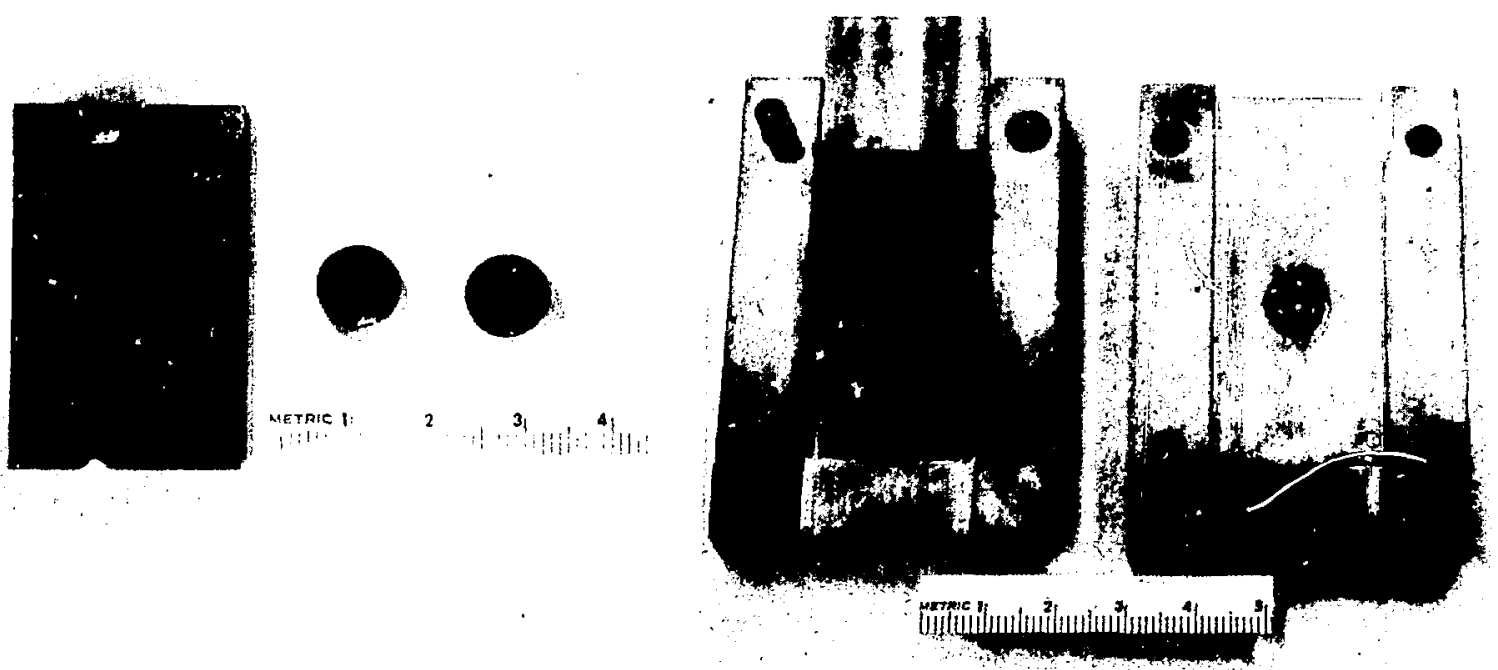

(a)

Fig. I-4.

(b)

Shear strength test assembly for GPHS locking members. (a) FWPF locking plate and bulk graphite locking members and (b) graphite components in test fixture. 

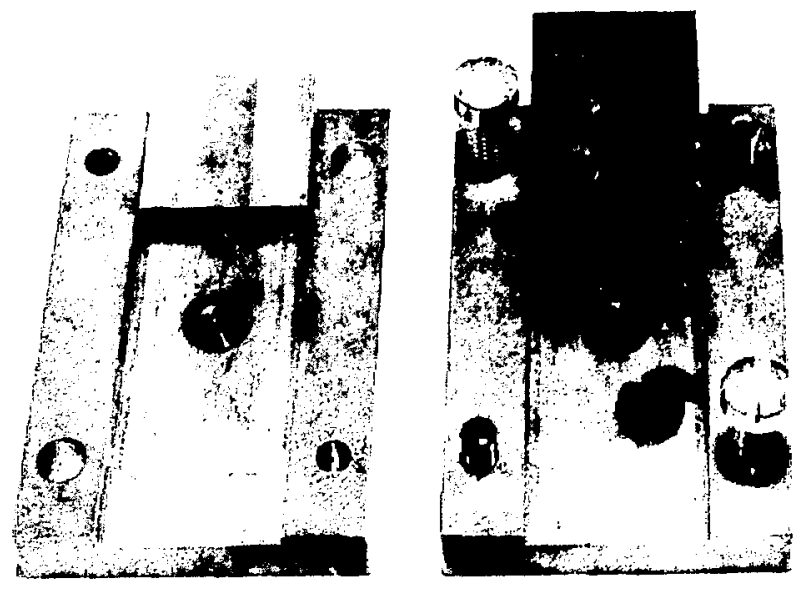

Fig. I-5.

Appearance of failed lock member assembly after test.

II. ENVIRONMENTAL STUDIES

A. Terrestrial Environments

1. Environmental Chamber Experiments.. Six terrestrial environmental chamber experiments are under way as described in Table II-1.

The fragments of Pressed Plutonium Oxide (PPO) greater than $6 \mathrm{~mm}$ in diameter $(224 \mathrm{~g})$ that resulted from the impact test of MHFT-12 have been exposed to simulated humid weather conditions on loam soil for 2409 days. The environmental system was programmed for summer conditions (20 to $40^{\circ} \mathrm{C}, 87$ to $95 \% \mathrm{RH}$ ) for 174 days, followed by 182 days under winter conditions ( 0 to $17^{\circ} \mathrm{C}, 71$ to $100 \% \mathrm{RH})$. The system was then operated for 173 days of its second summer, 207 days of the second winter, 193 days of the third summer, 169 days of the third winter, 211 days of the fourth summer, 174 days of the fourth winter, 195 days in its fifth summer, 154 days in its fifth winter, 168 days in its sixth summer, 185 days in its sixth winter, and 178 days in its seventh summer, before being programmed for its seventh winter. The averages of the plutonium contents from liquid scintillation analys is and the volume measurements of the water that percolated through the soil for the first five $32-\mathrm{mm}$ winter rains show the increase in volume expected for the change to winter conditions, but the plutonium content was almost unchanged (Table II-2). The average water volume was 8.9 \&, compared with 5.0 \& last month, while the average plutonium content decreased slightly from 1.7 to $1.6 \mu \mathrm{Ci}$. The rate of plutonium collection by the dehumidifier condensate stayed the same at $0.5 \mu \mathrm{Ci} / \mathrm{wk}$.

The finer fraction of MHFT-12, which consists of $28 \mathrm{~g}$ of PPO particles with diameters between 0.01 and $6 \mathrm{~mm}$, was placed on loam soil and subjected to 110 days of humid summer conditions, followed by 147 days of humid winter weather. Subsequently, the seasons changed on the same days as in the chamber containing the large pieces. It has now been in its seventh winter for 43 days. The average of the measured volumes for four $32-\mathrm{mm}$ rains is higher, as is the aver- 
TABLE II-1

TERRESTRIAL ENVIRONMENTAL CHAMBER EXPERIMENTS

Experiment Number

1

3

6

7

8

10
Description

MHFT-12 chunks on 1oam;

humid climate

MHFT-12 fines on loam,

humid climate

MHFT-50 fines on loam;

circular soil partitioner;

humid climate

MHFT-27 fines on sand;

arid climate

MHFT-50 chunks on loam;

circular soil partitioner;

humid climate

MHFT-27 chunk on sand;

arid climate
Date

Started

$6-21-73$

$9-27-73$

$4-9-75$

$2-25-75$

$4-9-75$

$2-26-75$

age plutorium content (Table III-3). A fifth rain of $153 \mathrm{~mm}$ was not averagea with rest, as it would be expected to have a much higher volume and plutonium content. The average volume increased from 3.3 to $3.8 \ell$, the average plutonium content from 0.36 to $0.53 \mu \mathrm{Ci}$. The collection rate for plutonium by the dehumidifier condensate increased from 0.24 to $\mathrm{i} .06 \mathrm{\mu Ci} / \mathrm{wk}$.

The fragments of PPO greater than $6 \mathrm{~mm}$ in diameter $(221 \mathrm{~g})$ from the impact test of MHFT-27 have been on sand in an environmental chamber programmed for arid winter conditions $\left(3\right.$ to $28^{\circ} \mathrm{C}, 21$ to $87 \% \mathrm{RH}$ ) for 122 days, under arid summer conditions $\left(26\right.$ to $53^{\circ} \mathrm{C}, 7$ to $\left.33 \% \mathrm{RH}\right)$ for 196 days, under arid winter conditions again for 137 days, under arid summer conditions again for 211 days, in the third arid winter for 188 days, in the third summer for 181 days, 155 days in the fourth arid winter, 169 days in its fourth arid summer, 186 days in its fifth arid winter, 178 days in its fifth arid summer, and now in its sixth arid winter for 43 days. Liquid scintillation analys is and volume measurement of one $81 \mathrm{-mm}$ rain gave results of $0.36 \mu \mathrm{Ci}$ of plutonium in $11.2 \ell$, compared with $0.04 \mu \mathrm{Ci}$ in $2.8 \mathrm{l}$ last month. The collection rate for plutonium in the dehumidifier condensates was $0.10 \mu \mathrm{Ci} / \mathrm{wk}$, compared with $0.11 \mu \mathrm{Ci} / \mathrm{wk}$ last month.

The finer fraction of MHFT-27, $34 \mathrm{~g}$ of particles of PPO with diameters between 0.01 and $6 \mathrm{~mm}$, has experienced the same weather and soil conditions as the larger pieces. Volume measurement and liquid scintillation analysis of 
TABLE I I-2

PLUTONIUM IN PERCOLATED RAINWATER

(LARGE PIECES FROM MHFT-12)

$\begin{array}{llcc}\text { No. } & \text { Date } & \begin{array}{c}\text { Vol. Collected } \\ (\ell)\end{array} & \begin{array}{c}\text { Pu Found } \\ (\mu \mathrm{C} i)\end{array} \\ 332 & 12 / 17 & 6.6 & 1.2 \\ 333 & 12 / 26 & 8.4 & 1.4 \\ 334 & 1 / 2 & 9.0 & 1.8 \\ 335 & 1 / 7 & 17.2 & 2.2 \\ 336 & 1 / 14 & \underline{9.3} & 1.5 \\ \text { Average } & & 8.9 & 1.6\end{array}$

water that percolated through the soil for one $81-m m$ rain gave results of 0.185 $\mu \mathrm{Ci}$ of plutonium in $6.4 \mathrm{l}$ of water, higher in plutonium than the $0.008 \mu \mathrm{Ci}$ of plutonium in 2.6 \& of water for the last rain. The dehumidifier condensates collected $0.08 \mu \mathrm{Ci} / \mathrm{wk}$ of plutonium, higher than the $0.07 \mu \mathrm{Ci} / \mathrm{wk}$ last month.

The pieces $(186 \mathrm{~g})$ of PPO greater than $2 \mathrm{~mm}$ in diameter from MHFT-50 after an impact test have been on loam soil in an environmental test chamber programmed for humid winter conditions for 79 days, under humid summer weather for 193 days, under winter humid conditions for 169 days, under summer humid conditions again for 211 days, under winter humid conditions for the third time for 188 days, in the third summer for 181 days, in the fourth winter for 155 days, in the fourth summer for 167 days, in the fifth winter for 185 days, 178 days in the fifth summer, and now 43 days into the sixth winter. The soil in this

TABLE II-3

PLUTONIUM IN PERCOLATED RAINWATER

(FINE MATERIAL FROM MHFT-12)

\begin{tabular}{llcc} 
No. & Date & $\begin{array}{c}\text { Vol. Collected } \\
(\ell)\end{array}$ & $\begin{array}{c}\text { Pu Found } \\
(\mu \mathrm{CC})\end{array}$ \\
\cline { 3 - 3 } 324 & $12 / 17$ & 4.0 & 0.57 \\
325 & $12 / 26$ & 6.8 & 1.40 \\
326 & $1 / 2$ & 0.8 & 0.02 \\
327 & $1 / 7$ & $\underline{3.5}$ & 0.13 \\
Average & & 3.8 & 0.53 \\
328 & $1 / 14$ & 104. & 10
\end{tabular}


TABLE I I-4

PLUTONIUM IN PERCOLATED RAINWATER

(LARGER PIECES FROM MHFT-50 ON COMPARTMENTED SOIL)

\begin{tabular}{|c|c|c|c|c|c|c|}
\hline \multirow[b]{2}{*}{ No. } & \multirow[b]{2}{*}{ Date } & \multirow[b]{2}{*}{$\begin{array}{c}\text { Rainfall } \\
(\mathrm{mm}) \\
\end{array}$} & \multicolumn{2}{|c|}{ Inner } & \multicolumn{2}{|c|}{ Outer } \\
\hline & & & $\begin{array}{l}\text { Vol } \\
(\ell) \\
\end{array}$ & $\begin{array}{c}\mathrm{Pu}_{\mathrm{u}} \\
(\mu \mathrm{Ci})\end{array}$ & $\begin{array}{l}\text { Vol } \\
(\ell) \\
\end{array}$ & $\begin{array}{l}\mathrm{Pu} \\
(\mu \mathrm{Ci})\end{array}$ \\
\hline $\begin{array}{l}241 \\
242 \\
243 \\
244 \\
245\end{array}$ & $\begin{array}{l}12 / 17 \\
12 / 26 \\
1 / 2 \\
1 / 7 \\
1 / 14\end{array}$ & $\begin{array}{l}34 \\
34 \\
34 \\
23 \\
34\end{array}$ & $\begin{array}{l}1.4 \\
1.4 \\
1.4 \\
1.8 \\
3.2\end{array}$ & $\begin{array}{l}0.070 \\
0.019 \\
0.089 \\
0.167 \\
0.157\end{array}$ & $\begin{array}{r}11.8 \\
13.2 \\
14.5 \\
8.2 \\
14.5\end{array}$ & $\begin{array}{l}0.14 \\
0.10 \\
0.11 \\
0.36 \\
0.17\end{array}$ \\
\hline Aver & & & 1.8 & 0.100 & 12.4 & 0.18 \\
\hline
\end{tabular}

chamber is divided into two compartments. A thin cylindrical 45-cm-diameter steel shell separates the central portion of the soil, which contains the PPO, from the outer portion. The rainwater that percolates through the soil in the two compartments is collected separately for analysis. In the liquid scintiliation analys is and volume measurements of rainwater from five rains, the average values for both compartments are higher this month except for the average plutonium content of the inner compartment, which changed very little (Table II-4). In the inner compartment the average volume was $1.8 \ell$ and the average plutonium content was $0.100 \mu \mathrm{Ci}$, compared with $1.5 \mathrm{l}$ and $0.109 \mu \mathrm{Ci}$ last month. In the outer compartment the average volume increased from 11.2 to $12.4 \mathrm{\ell}$, the plutonium content from 0.13 to $0.18 \mu \mathrm{Ci}$. The rate of collection of plutonium by the dehumidifier condensate increased from 0.7 to $2.0 \mu \mathrm{Ci} / \mathrm{wk}$.

The fine particles $(68 \mathrm{~g})$ of MHFT-50, with particle diameters between 0.01 and $2 \mathrm{~mm}$, have experienced the same weather conditions as the larger pieces and are also on loam in a similarly compartmented tray. Liquid scintillation analyses and measured volumes of percolated rainwater from five rains show decreases in the average volumes and plutonium contents for both cumpartments (Table II-5). The averages for the outer compartment volumes and plutonium contents are $3.2 \ell$ and $0.104 \mu \mathrm{C} i$, respectively, compared with $5.1 \ell$ and 0.142 $\mu \mathrm{Ci}$ last month. The inner compartment averages are $1.3 \mathrm{\ell}$ and $0.015 \mu \mathrm{Ci}$, compared with $3.0 \mathrm{l}$ and $0.036 \mu \mathrm{Ci}$ last month. The collection rate for plutonium in the dehumidifier condensate changed from 0.4 to $0.2 \mu \mathrm{Ci} / \mathrm{wk}$.

The experiment in which a $254-\mathrm{g}$ sphere of plutonium dioxide clad with iridium and encased in a Graphite Impact She11 (GIS), MHFT-23, was on sand under alternate winter and summer humid conditions for 1103 days was terminated April 17, 1978. A draft of the topical report for this experiment has been prepared and is being reviewed.

2. Terrarium Experiments. Chambers 5 and 9 have been fitted with fluorescent lights so that they can be used to measure plutonium uptake in growing plants and simple animals. A 24-h timer, wired to control the 1ights, was installed in each chamber and set in a summer cycle (sunrise at 7 AM and sunset at $8 \mathrm{PM}$ ). Blue grass was planted in each chamber, but two temperature excursions killed the grass in chamber 9 . Baffles had been installed in the airstream of 
TABLE II -5

\section{PLUTONIUM IN PERCOLATED RAINWATER \\ (FINE MATERIAL FROM MHFT-50 ON COMPARTMENTED SOIL)}

\begin{tabular}{|c|c|c|c|c|c|c|}
\hline \multirow[b]{2}{*}{ No. } & \multirow[b]{2}{*}{ Date } & \multirow[b]{2}{*}{$\begin{array}{l}\text { Rainfall } \\
(\mathrm{mm})\end{array}$} & \multicolumn{2}{|c|}{ Inner } & \multicolumn{2}{|c|}{ Outer } \\
\hline & & & $\begin{array}{l}\overline{V o T} \\
(\ell) \\
\end{array}$ & $\begin{array}{c}\mathrm{Pu} \\
(\mu \mathrm{Ci})\end{array}$ & $\begin{array}{l}\overline{V o l} \\
(\ell) \\
\end{array}$ & $\begin{array}{r}\mathrm{Pu} \\
(\mu \mathrm{C} i) \\
\end{array}$ \\
\hline $\begin{array}{l}242 \\
243 \\
244 \\
245 \\
246\end{array}$ & $\begin{array}{l}12 / 17 \\
12 / 26 \\
1 / 2 \\
1 / 7 \\
1 / 14\end{array}$ & $\begin{array}{l}24 \\
24 \\
24 \\
23 \\
23\end{array}$ & $\begin{array}{l}2.0 \\
1.1 \\
0.9 \\
1.8 \\
0.7\end{array}$ & $\begin{array}{l}0.018 \\
0.015 \\
0.015 \\
0.019 \\
0.009\end{array}$ & $\begin{array}{l}3.0 \\
3.9 \\
2.5 \\
2.6 \\
4.0\end{array}$ & $\begin{array}{l}0.098 \\
0.127 \\
0.081 \\
0.075 \\
0.137\end{array}$ \\
\hline \multicolumn{2}{|c|}{ Average } & & 1.3 & 0.015 & 3.2 & 0.104 \\
\hline
\end{tabular}

these chambers to reduce the effect of strong winds, which seem to be inimical to the growth of the grass, probably because of rapid drying of the soil. The grass has been cut regularly and the cuttings analyzed for plutonium to establish a blank, which is $0.5 \mathrm{pCi} / \mathrm{g}$, a value that is probably not significantly different from our lower detection limit. An improved method of cutting the jrass is being sought, preparatory to the introduction of plutonium. The grass in chamber 9 has been replanted. Equipment to correct the control problem in this chamber has been installed.

3. Soil Column Experiments. Three soil columns experiments are under way to test the transport of plutonium derived from plutonium oxide particles on the soil surface. The soil columns are made of silt loam soil, $\sim 14 \mathrm{~cm}$ high and $2.5 \mathrm{~cm}$ in diameter. These columns are identified as 7,8 , and 9 . Column 7 has $3.5 \mathrm{mg}$ of $\mathrm{PuO}_{2}$ particles on its soil surface, with a particle size distributionmainly in the 40- and 60-diameter range, column 8 contains $2.2 \mathrm{mg} \mathrm{PuO}_{2}$ particles with an average diameter of $12 \mu \mathrm{m}$, and 9 contains $2.6 \mathrm{mg}$ with an average diameter of $7 \mathrm{\mu m}$. These three size ranges are from the same three batches of plutonia particles that we are using in the experiments for measuring dissolution rate as a function of particle size. The columns are being eluted with distilled water (a rainwater simulant). The columns have been in operation for 1164 days. Measurements made after 1056 days of operation (Table II-6) show that the flow rates have not changed significantly. The variation in flow rate between columns is unexpected, inasmuch as they all contain soil from the same source. Radiation measurement show that at least $99 \%$ of the $\mathrm{PuO}_{2}$ particles still remain at the top of each column; radiation caninot be detected from any particle that may move downward into the soil columns. Almost $90 \%$ of the plutonium found in the eluates was in the collection representing the first 5 days of operation. This was probably from the water suspension of particles used to place the particles on the columns.

\section{B. Aquatic Environments}

1. Aqueous Release Rates As A Function of $\mathrm{PuO}_{2}$ Particle Size. Three sets of sized ${ }^{3{ }^{3} \mathrm{PuO}_{2}}$ particles, each having a different size distribution, are 
TABLE II-6

$\mathrm{PU}$ TRANSPORT FROM PUO 2 PARTICLES

Column

7
8
9
Elution Duration

\begin{tabular}{|c|c|c|c|}
\hline \multicolumn{2}{|c|}{1066 days } & \multicolumn{2}{|c|}{1164 days } \\
\hline $\begin{array}{l}\text { Total Vol } \\
(e)\end{array}$ & $\begin{array}{l}\text { Total Pu } \\
\text { (ng) }\end{array}$ & $\begin{array}{c}\text { Total Vol } \\
\text { (l) }\end{array}$ & $\begin{array}{c}\text { Total } \mathrm{Pu} \\
\text { (ng) } \\
\end{array}$ \\
\hline $\begin{array}{l}77.4 \\
67.4 \\
35.8\end{array}$ & $\begin{array}{l}30.3 \\
27.0 \\
39.9\end{array}$ & $\begin{array}{l}83.8 \\
73.2 \\
39.3\end{array}$ & $\begin{array}{l}31.5 \\
20.4 \\
40.9\end{array}$ \\
\hline
\end{tabular}

suspended in $1 \mathrm{M} \mathrm{HClO}_{4}$ in 50-me volumetric flasks in a $37^{\circ} \mathrm{C}$ water bath. Periodicaliy samples are removed, centrifuged to remove suspended particles, and then analyzed for plutonium. These data are needed to obtain information about dissolution under carefully controlled solution conditions and to determine the effects of particle size on dissolution rates.

The data (Table II-7) have been collected for 1534 days for the three particle size distributions. Each of these particle size distributions was used to prepare 4 experiments, 2 containing $2 \mathrm{mg}$ of particles and 2 containing $10 \mathrm{mg}$. Distribution $A$ consists of the largest particles, having a size range of $\sim 1$ to $120 \mathrm{\mu m}$. Distribution $B$ is intermediate in particle size and distribution $C$ contains a preponderance of the smallest particles. The dissolution rates, grams dissolved/second ( $\mathrm{g} / \mathrm{s})$, have changed only slightly during the past 3 months, and, as expected, the smaller particles release plutonium at a faster rate than the larger ones.

A comprehensive review of this experiment, including a more detailed characterization of the three particle distributions, has been completed. The review revealed that the large particles in distribution $A$ were actualiy aggregates of smaller particles. The suspension technique used in the particle sizing produced a combination of "large particles" (did not suspend) and small particles thought to be individual members of aggregates that had broken apart. It is not possible to determine a quantitative estimate for the amount represented by the large fraction, therefore, the calculation of an available surface area is not possible.

Distribution $B$ contained both large and small particles. In this case the large particles consisted of a preponderance of single large particles with some fines adhering to them, whereas the large particles in distribution $A$ consisted of aggregates of similar size particles. Again, it is not possible to determine a total surface area because the sizing technique does not produce a quantitative estimate for the amount represented by each fraction.

Distribution $C$ behaved normally in that all particles could be suspended and there were no anomalous large particles. This distribution lends itself to a calculation of total surface area but there is no assurance that the initial area has remained constant. In fact, it can be argued that the surface area has changed during the course of the experiment.

Grains dissolved versus time plots of representative experiments $(A-1, B-1$, $C-1)$ exhibits no discernible discrepancies. Each plot shows increasing dissolution of ${ }^{238} \mathrm{PuO}_{2}$ with $\mathrm{C}-1>\mathrm{B}-1>\mathrm{A}-1$. Integral dissolution rate plots show 
TABLE II-7

SUMMARY OF DISSOLUTION EXPERIMENT IN 1 M $\mathrm{HClO}_{4}$

\begin{tabular}{|c|c|c|c|c|}
\hline \multirow[b]{2}{*}{$\begin{array}{c}\text { Experiment } \\
\text { Number }\end{array}$} & \multirow[b]{2}{*}{$\begin{array}{l}\mathrm{PuO}_{2} \\
\text { (mg) }\end{array}$} & \multirow[b]{2}{*}{$\begin{array}{l}\text { Percent } \\
\text { Dissolved }\end{array}$} & \multicolumn{2}{|c|}{ Dissolution Rate } \\
\hline & & & $(g / s)$ & $(g / s-g)$ \\
\hline $\begin{array}{l}\text { A1 } \\
\text { A2 } \\
\text { A3 } \\
\text { A4 }\end{array}$ & $\begin{array}{r}2.02 \\
2.05 \\
10.19 \\
9.90\end{array}$ & $\begin{array}{l}4.8 \\
4.5 \\
4.5 \\
4.5\end{array}$ & $\begin{array}{l}7.3 \times 10^{-13} \\
6.9 \times 10^{-13} \\
3.5 \times 10^{-12} \\
3.4 \times 10^{-12}\end{array}$ & $\begin{array}{l}3.6 \times 10^{-10} \\
3.4 \times 10^{-10} \\
3.4 \times 10^{-10} \\
3.4 \times 10^{-10}\end{array}$ \\
\hline $\begin{array}{l}\text { B1 } \\
\text { B2 } \\
\text { B3 } \\
\text { B4 }\end{array}$ & $\begin{array}{r}2.02 \\
2.03 \\
10.25 \\
10.45\end{array}$ & $\begin{array}{l}8.2 \\
9.7 \\
8.4 \\
8.5\end{array}$ & $\begin{array}{l}1.3 \times 10^{-12} \\
1.5 \times 10^{-12} \\
6.6 \times 10^{-12} \\
6.8 \times 10^{-12}\end{array}$ & $\begin{array}{l}6.2 \times 10^{-10} \\
7.3 \times 10^{-10} \\
6.5 \times 10^{-10} \\
6.5 \times 10^{-10}\end{array}$ \\
\hline $\begin{array}{l}\mathrm{Cl} \\
\mathrm{C2} \\
\mathrm{C} 3 \\
\mathrm{C} 4\end{array}$ & $\begin{array}{r}2.23 \\
2.31 \\
9.89 \\
10.67\end{array}$ & $\begin{array}{l}18.6 \\
17.7 \\
17.8 \\
17.4\end{array}$ & $\begin{array}{l}3.2 \times 10^{-12} \\
3.1 \times 10^{-12} \\
1.3 \times 10^{-11} \\
1.4 \times 10^{-11}\end{array}$ & $\begin{array}{l}1.4 \times 10^{-9} \\
1.3 \times 10^{-9} \\
1.4 \times 10^{-9} \\
1.3 \times 10^{-9}\end{array}$ \\
\hline
\end{tabular}

significant differences among the three experiments. A-1, coarse particles, has a shallow minimum at $\sim 3 \times 10^{7} \mathrm{~s}$, whereas $B-1$, medium size particles, has a low maximum at $\sim 2 \times 10^{7} \mathrm{~s}$. C -1 , fine particles, exhibits a strong maximum at $22 \times 10^{7} \mathrm{~s}$ and has since decreased by $30 \%$. The maximum is 3 times that of $B-1$. It can be postulated that the initial rapid increase in the dissolution rate of $\mathrm{C}-1$ represents the solubilization of the smallest particles. The rate is now decreasing because of the reduction in surface area since only "larger" particles remain.

The third column in Table II-7 lists the percent of original material that has dissolved. Since a substantial amount of the original material has dissolved, $\sim 17 \%$ in the case of experiment $C$, the distribution of particles in each experiment may have changed considerably. An ultrafiltration technique is being investigated whereby the size distribution in each sample may be determined. If the technique is successful part or all of the experiment will be terminated.

An extraction procedure, designed to extract on $7 y \mathrm{Pu}^{+4}$, is being applied to these experiments. Preliminary results indicate that the plutonium in solution is $90 \%$, or greater, in the ionic form. Work is continuing in this area.

\section{Fuel Form Exposures.}

a. Seawater. The large 25-W pellet, HPZ-59-4, has been in cold seawater for 1923 days (Table II-8). Its release rate is $14 \mathrm{nCi} / \mathrm{m}^{2}-\mathrm{s}$, down $12 \%$ from last month.

The tidal simulation aquarium, using the 19-W source HPZ-186-4, has been under way for 814 days. The source is on sand in a stainless steel tray that is lowered into the water and subsequently raised above the surface twice 
TABLE II -8

SUMMARY OF

PU RELEASE RATE FROM PPO IN! AQUATIC ENVIRONMENTS

\begin{tabular}{|c|c|c|c|c|c|}
\hline Sample & $\begin{array}{l}\text { Power } \\
\text { (W) }\end{array}$ & $\begin{array}{c}\text { Immers ion } \\
\text { (days) }\end{array}$ & Water & $\begin{array}{l}\text { Temperature } \\
\text { (C) }\end{array}$ & $\begin{array}{l}\text { Release Rate } \\
\left(\mathrm{nCi} / \mathrm{m}^{2}-\mathrm{s}\right)\end{array}$ \\
\hline HPZ $-60-2$ & 2.5 & 2130 & Fresh & 10 & $\begin{array}{l}130 \\
370\end{array}$ \\
\hline HPZ-111-1 & 25 & 1829 & Fresn & 10 & 370 \\
\hline HPZ-59-4 & 25 & 1923 & Sea & 10 & 14 \\
\hline HPZ-174 & 18 & 818 & Sea & 10 & 6 \\
\hline HPZ-186-4 & 19 & 814 & Sea (Tidal) & 10 & 56 \\
\hline
\end{tabular}

every 24 hours. Figure II- 1 is a plot of plutonium concentration $i r_{i} \mu \mathrm{g} / \ell$ versus time for the tidal simulation experiment. On day 103 (point A on Fig. II-i) a crack was observed on the face of the source and on day 393 (B) the source had split into two pieces. By day 404 (C) the source had separated into seven pieces. On day 451 (D) the elevator motor failed and the source was left submerged in the seawater. On day 481 (E) a sample of the source was removed for metallurgical examination and five sand samples were cbtained from the tray on the bottom of the aquarium. At the present time the source is fragmented into 30 or more pieces. Therefore, a calculation of release rate per unit area is not possible because there is no reasonable estimate of the source surface area. On the basis of its original area, the release rate is $56 \mathrm{nCi} / \mathrm{m}^{2}-\mathrm{s}$, down $5 \%$ from last month's value.

The five sand samples, taken from the four corners and the center of the tray, were analyzed for plutonium content. The results ranged from $55.1 \mathrm{\mu g}$ to $26.2 \mu \mathrm{g}$ with an average of $42 \pm 12 \mu \mathrm{g}$. Based on this average and on the surface areas of the sand tray and the sand samples it can be estimated that there are $28 \mathrm{mg}$ of plutonium on or in the sand.

The 18-W pellet HPZ-174 has been immersed in seawater at $10^{\circ} \mathrm{C}$ for 818 days. The release rate is $6 \mathrm{nCi} / \mathrm{m}^{2}-\mathrm{s}$, down $14 \%$ from the value for the last 4 months. This is the same system in which we maintained a live sea cucumber for 230 days. b. Fresh Water. The 2.5-W pellet, HPZ-60-2, is part of a set of experiments to compare release rates from PPO in seawater and in fresh water. Its average release rate after 2130 days of immersion is $130 \mathrm{nCi} / \mathrm{m}^{2}-\mathrm{s}$, unchanged from last month's value. This is the second highest release rate observed in this set of PPO pellets.

The fastest release rate is shown by the 25-W pellet, HPZ-111-1, immersed for 1829 days at $10^{\circ} \mathrm{C}$. Its average release rate is $370 \mathrm{nCi} / \mathrm{m}^{2} \mathrm{~s}$, down $5 \%$ from the value observed last month. The highest rates from PPO are found in $10^{\circ} \mathrm{C}$ fresh water, and the lowest in warm seawater. There is little, if any, rate difference caused by a 10-fold difference in power level.

c. Source Term. The plutonium release rates shown in Table II-8 are essentially minimum release rates in that the removal of plutonium by deposition on underwater surfaces cannot be measured. A total release rate, or source term, is not obtainable in an aquarium experiment. Therefore, a glass chamber was designed and constructed to permit such measurements. 12 


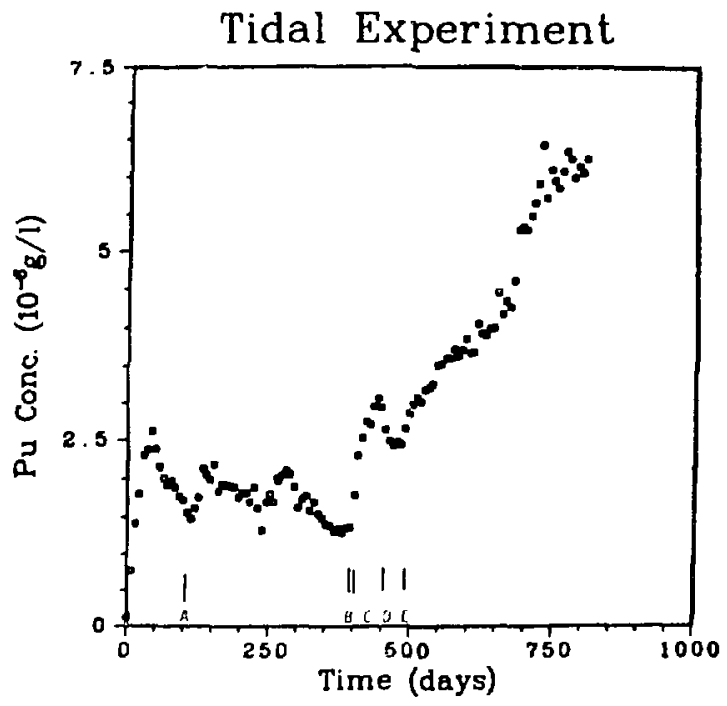

Fig. II-1. Plutonium concentration in the Tidal Sumulation Experiment.

This chamber is a 15.25-cm i.d. cylinder, 25.4-cm tall. It can be separated into two parts by means of an 0-ring joint midway up the cylinder. The top half has a side arm for attaching a membrane filter and an 0-ring sealed port through which water samples can be withdrawn. The bottom half contains a glass pedestal for positioning the plutonium source.

A 48.6-g, bare ${ }^{238}{ }^{8} \mathrm{PuO}_{2}$, source, $\mathrm{HPZ}-186-2$, was positioned in an empty glass chamber on December 20, 1977, and the chamber was placed in an aquarium at $10^{\circ} \mathrm{C}$ for temperature control. This experiment will provide baseline data for an unclad source exposed to air only. Such conditions occur in some of the environmental chambers. The $0.05-\mu m$ pore-size filter is changed weekly and and lyzed for ${ }^{238} \mathrm{Pu}$. This experiment was terminated on day 454 . Only 2 filters out of 63 had shown any plutonium, $6 \mathrm{pg}$ on one and $2 \mathrm{pg}$ on the other. Neither result was confirmed by subsequent filters and are, therefore, attributed tc contamination from an unknown source external to the experiment. ihe source was transferred to a second chamber and the first chamber was resealed and transferred for analysis. The source in the second chamber was submerged in deionized water for 30 min and then removed. At this point the source fraitured into three pieces and further experiments with this source were cancelled. The second chamber was resealed in preparation for analysis.

Analysis of the first chamber consisted of the quantitative recovery of the ${ }^{23{ }^{8} \mathrm{PuO}_{2}}$ on the interior surfaces. This was accomplished using a $\mathrm{HNO}_{3}-\mathrm{HF}$ leach followed by a wash with a decontamination solution. No residual activity could be detected on the surfaces available for monitoring.

The total ${ }^{238} \mathrm{Pu}$ recovered was $1.41 \mu \mathrm{g}$, which represents a release rate per unit surface area of $22.1 \mathrm{pg} / \mathrm{m}^{2}-\mathrm{s}$. This number can be compared to the release rates seen in the aquatic environment experiments which vary from 0.59 to 36 $\mathrm{ng} / \mathrm{m}^{2} \mathrm{~s}$. The analysis of the second part of the experiment in which the source was submerged indicated the release of $49.3 \mu \mathrm{g}$. Calculations based on the same surface area and a 30-minute submergency yields a release rate of $16.8 \mu \mathrm{g} / \mathrm{m}^{2}-\mathrm{s}$. This calculation may be invalid since the initial release may be that of loose material on the "old" surface of the source. The next experiment, that of the release from a "new" surface of the same source, could not be performed because the source broke into three parts. 
Four glass chambers are being prepared for the next sequence of experiments. These experiments will use GROG type source material and will consist of two fresh water systems and two simulated seawater systems, one each at $10^{\circ} \mathrm{C}$ and one each at $37^{\circ} \mathrm{C}$. This sequence should provide information on the effects of the type of water used and the temperature of the water.

When the four chambers were placed in two aquariums, three chambers leaked at the center seal. Neoprene rubber gaskets were found to provide a suitable seal. These experiments will be initiated during the next report period.

d. Water Samplers. Two water samples were shipped to the Naval Ocean Systems Center at San Clemente Island. On May 15, 1979, the two samplers were attached to two cages and placed on the ocean floor. One sampler was placed in the Cermet area and activated by navy divers. The second sampler was placed and activated on the ocean floor approximately 60 feet NNE of the first unit. These two units were designed to collect $1.5 \mathrm{l}$ of water in 90 days. They have been received back at Los $A 1$ amos.

Sample \#1 has been opened and the contents removed. Severe corrosion was observed on all four valves and a deposit was found on the interior walls and on the top of the piston. This deposit was easily removed with a water wash and a light rubbing. Samp?es of the interior deposit and samples of the deposit on the exterior of the sampler will be submitted for elemental analyses.

The total seawater sample obtained during the 3-month sampling period amounted to $440 \mathrm{ml}$. It was noted that the lower receiver had lost its vacuum. Corrosion of the vacuum valve may have resulted in this vacuum loss and subsequent equalization of the pressure on both sides of the piston which terminated sampling.

The $440 \mathrm{~m} \ell$ sample, the sludge deposit, and the tissue used to wipe the irterior walls were treated with $\mathrm{HNO}_{3}-\mathrm{HClO}_{4}$. The resulting solution was highly colored (yellow) which produced considerabie quenching during liquid scintillation counting. Therefore, the sample was split into four aliquots. Two al iquots were processed using a microporous anion exchange resin. This procedure had been previously tested with simulated seawater spiked with ${ }^{2}{ }^{38} \mathrm{Pu}$ in the concentration range expected in the water sampler's. The recovery of plutonium for the test with the spiked simulated seawater was $96 \pm 10 \%$. However, when the aliquots of the solution from the water sampler were processed by this anion exchange resin procedure, values of 230 and $13 \mathrm{~d} / \mathrm{m}$ were obtained. Because the first aliquot was hancled in an area where cross contamination was possible, the high value was discarded. The aliquots processed by lanthanum fluoride precipitation produced values of $49 \mathrm{~d} / \mathrm{m}$ and $16 \mathrm{~d} / \mathrm{m}$. The three aliquots give an average of $(9.6 \pm 7.3) \times 10^{-12} \mathrm{~g} / \ell$ for the concentration of ${ }^{238} \mathrm{Pu}$ in the seawater at the Cermet site. The second sampler, containing a seawater sample from outside the Cermet site, is being processed at this time.

C. Analytical Studies of $\mathrm{PuO}_{2}$-Soil Agglomeration

(Purchase Order LP9-3589K; LFE Environmental)

A progress report was not received from LFE Environmentai this month.

Cumulative costs on this purchase order through November, 1979 , were $\$ 5,752$, leaving a balance of $\$ 7828$. This purchase order has been extended to a new termination date of September 30,1980 . Final payment of $\$ 3775.68$ was made on the previous purchase order, LP-8-8136C, for a total payment of $\$ 18878.33$ at close out. 


\section{SYSTEMS SUPPORT}

A. Stirling Isotope Power System

The accumulated exposure iime for the $800^{\circ} \mathrm{C}$ test assembly was $18202 \mathrm{~h}$ as of February 1, 1980. We expect to remove this sample from test and examine it within the next two or three months in support of our efforts to evaluate the effects of the delayed Galileo launch on the heat source components.

B. Multi-hundred Watt

1. Impact Test. The Multi-hundred Watt (MHW) fueled sphere assembly

(FSA) MHFT-6T was examined after aging, reentry, and impact.

The components for this FSA were identified as follows:

$\begin{array}{ll}\text { Plutonia sphere } & : \text { HS-2 } \\ \text { Iridium Hemi-she11s } & \text { DOP-26 5-1 and 5-4 } \\ \text { GIS } & : 936837-2\end{array}$

The aging treatment consisted of $8834 \mathrm{~h}$ exposure at $1210^{\circ} \mathrm{C}$ (GIS) in vacuum. Continuous monitoring of the helium signal derived from the FSA during the aging treatment indicated that at least one vent remained opon throughout the test exposure.

Following a safety verification test reentry pulse to $1550^{\circ} \mathrm{C}$, post-impact containment she11 (PICS), the FSA was impacted at $74 \mathrm{~m} / \mathrm{s}$ and $1440^{\circ} \mathrm{C}$ (PICS). The cap of the GIS was orienced at $180^{\circ}$ to the initial impact point.

The height strain of the impacted post-impact sphere assembly (PISA) was $-23.5 \%$ and the diametral strain was $+6.9 \%$. Two 1 inear punch-through strains were observed on the impact face of the PISA, as shown in Fig. III-1(a) and in the profile views ( $b$ and $c$ ) in the figure. The iridium PICS was not breached at these locations.

Sma11 "fingerprint" type cracks were present on the impact fac", however, vicual examination of the interior of the PICS did not indicate thi $i$ there was penetration. The back side of the PISA showed several locations at which the iridium was stretched over the edge of fuel sphere fragments. No failures of the iridium occurred at tilese locations. Figure III-2 illustrates the mode of the fuel sphere crush-up. The shear plane between fuel fragments which resulted in one of the punch through strains of the PICS is evident in the section on the left-hand side of the photograph.

It is apparent that the lower velocity of impact $(74 \mathrm{~m} / \mathrm{s}$ vs the $85 \mathrm{~m} / \mathrm{s}$ used for the LES $0 / 9$ and Voyager MHW impact tests) resulted in decreased overall deformation of the PISA, however, a complete evaluation of the test will require metallographic determination of the iridium grain size and Auger analysis of grain boundary chemistry.

2. Iridium Impurity Effects. Wo have continued to examine the effect of impurities on iridium performance in MHW impacts. This month we concentrated on a further examination of the effect of phosphorus on grain growth. We reported previously that DOP-26 Ir-0.3\% W suffers enhanced grain growth when annea Ied in the presence of $\mathrm{P}_{2} \mathrm{O}_{5}$. However, a clear trend that phosphorus affects grain growth in Ir-0.3\% W PICS has never been established. Previous experiments with phosphorus effects on grain growth and grain boundary chemistry are summarized in the top portion of Table III-T. The effect of phosphorus available from $\mathrm{P}_{2} \mathrm{O}_{5}$ is clearly estab? ished. There is some different grain size response depending on the specific lot of DOP-26 alloy examined. 


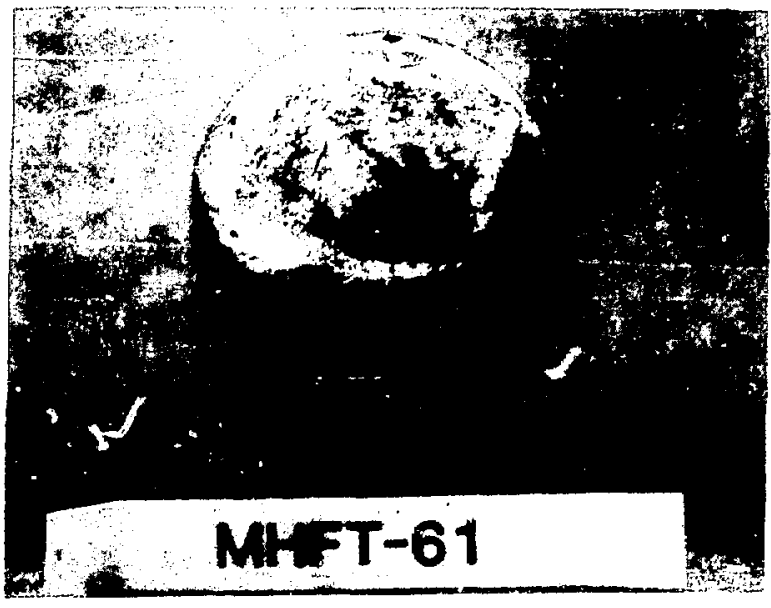

(a)

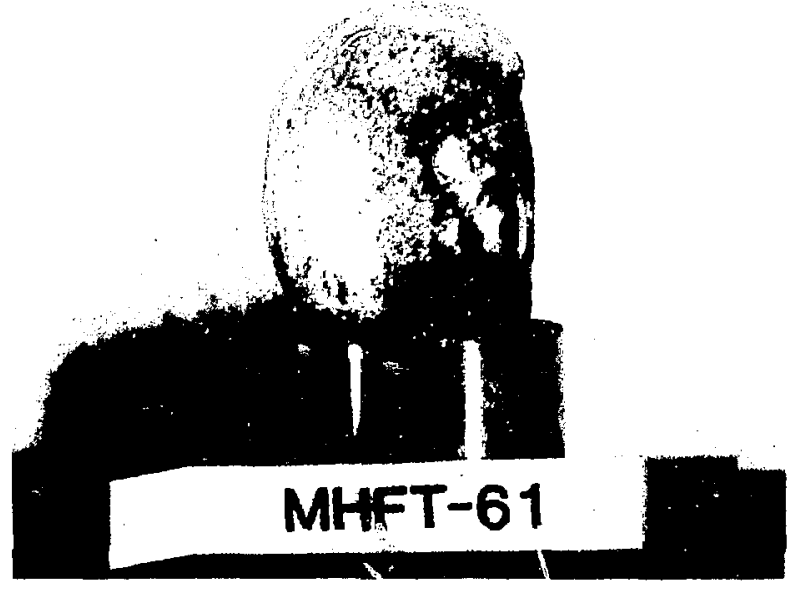

(b)

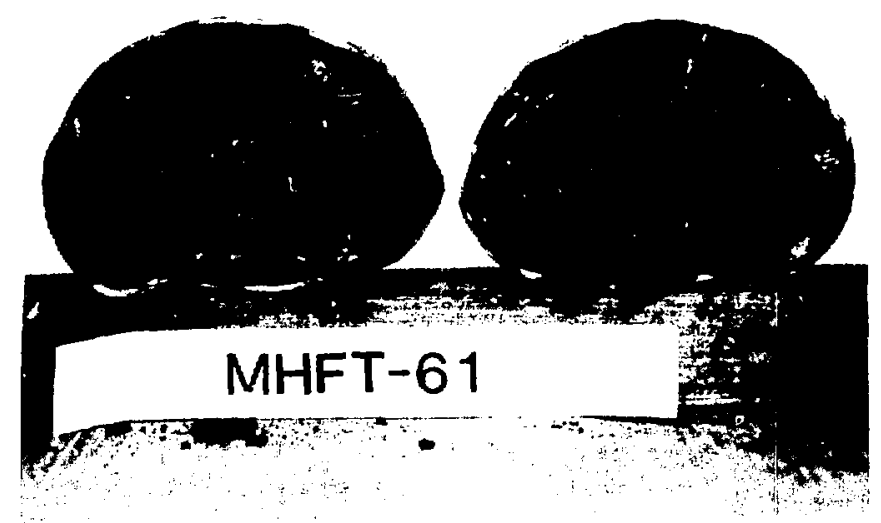

\section{Fig. III-1.}

Photographs of the impacted PISA from MHFT-61. (a) Impact face, and ( $b$ \& c) profile views.

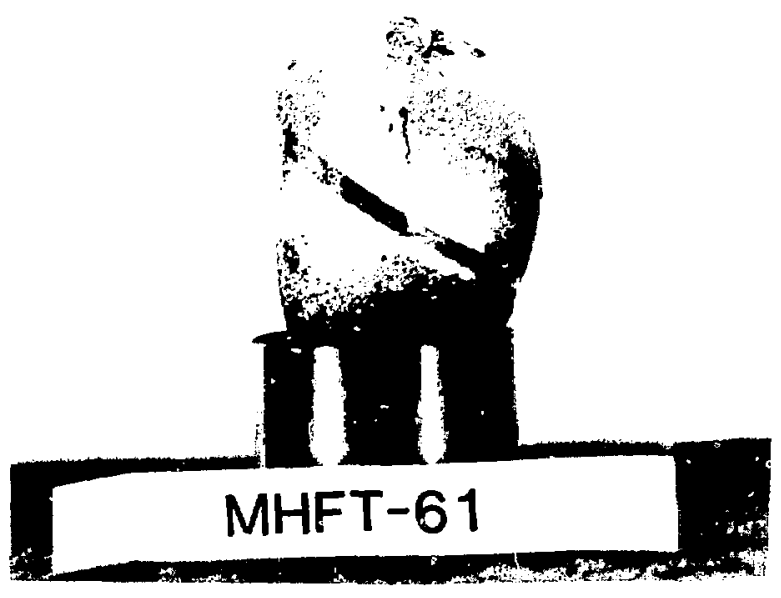

(c)
Fig. III-2.

Photograph of the impacted fuel sphere of MHFT-61. 
TABLE III-1

GRAIN SIZE AND AES RESULTS FOR P-DOPING

EXPERIMENTS ON I $\mathrm{r}-0.3 \% \mathrm{~W}$

\begin{tabular}{|c|c|c|c|c|c|}
\hline \multirow[b]{2}{*}{ Specimen } & \multirow[b]{2}{*}{ Lot } & \multirow[b]{2}{*}{ Irea tment } & \multirow[b]{2}{*}{$\begin{array}{c}\text { Grain Size } \\
\text { grains/thickness }\end{array}$} & \multicolumn{2}{|c|}{ Auger Intensities } \\
\hline & & & & $\mathrm{Th}_{65} / \mathrm{Ir}_{229}$ & $\mathrm{P}_{120} / \mathrm{Ir}_{229}$ \\
\hline $00 P-26$ & GPHS Lots & $\begin{array}{l}1 \mathrm{~h} \text { at } 1500^{\circ} \mathrm{C} \\
\text { in vacuum }\end{array}$ & $25-28$ & - & -- \\
\hline DOP-26 & GPHS Lots & $\begin{array}{l}\text { ig h at } 1500^{\circ} \mathrm{C} \\
\text { in vacuum }\end{array}$ & 13 & -- & -- \\
\hline$D O P-26$ & $\begin{array}{l}\text { Early OOP-26 } \\
\text { Lot, (1977) }\end{array}$ & $\begin{array}{l}18 \mathrm{~h} \text { at } 1575^{\circ} \mathrm{C} \\
\text { in vacuum }\end{array}$ & 8.5 & 0.60 & 0 \\
\hline OLMF $-8-65$ & $O L M F-8$ & $\begin{array}{l}19 \mathrm{~h} \text { at } 1575^{\circ} \mathrm{C} \\
\text { in vacuum }\end{array}$ & 7.4 & -- & -- \\
\hline$L-30-1$ & $L-30$ & $\begin{array}{l}19 \mathrm{~h} \text { at } 1575^{\circ} \mathrm{C} \\
\text { in vacuum }\end{array}$ & 6.2 & 0.34 & 0 \\
\hline DOP-26 & $\begin{array}{l}\text { Early } 00 \mathrm{P}-26 \\
\text { Lot. }(1977)\end{array}$ & $\begin{array}{l}18 \mathrm{~h} \text { at } 1575^{\circ} \mathrm{C} \\
\text { with } \mathrm{P}_{2} \mathrm{O}_{5}\end{array}$ & 5.6 & 0.81 & 0.40 \\
\hline I. $-30-5$ & $L-30$ & $\begin{array}{l}19 \mathrm{~h} \text { at } 1500^{\circ} \mathrm{C} \\
\text { with } \mathrm{P}_{2} 0_{5}\end{array}$ & 8.7 & 0.45 & 0.36 \\
\hline $0 L M F-8-61$ & OLMFF -8 & $\begin{array}{l}19 \mathrm{~h} \text { at } 1500^{\circ} \mathrm{C} \\
\text { with } \mathrm{P}_{2} 0_{5}\end{array}$ & 7.8 & 0.81 & 0.38 \\
\hline $0 L M F-8-44$ & OLMF-8 & $\begin{array}{l}1 \mathrm{~h} \text { at } 1500^{\circ} \mathrm{C} \\
\text { with } \mathrm{P}_{2} \mathrm{O}_{5}\end{array}$ & 19 & 0.82 & 0.47 \\
\hline $0 L M F-8-44 B$ & $0 L M F-8$ & $\begin{array}{l}1 \mathrm{~h} \text { at } 1500^{\circ} \mathrm{C} \text { with } \\
\mathrm{P}_{205}+18 \mathrm{~h} \text { at } 1500^{\circ} \mathrm{C} \\
\text { in vacuum }\end{array}$ & 4.7 & -- & -- \\
\hline OLMF $-8-5$ & OLMF- -8 & $\begin{array}{l}18 \mathrm{~h} \text { at } 1500^{\circ} \mathrm{C} \text { in } \\
\text { vacuum }+1 \mathrm{~h} \text { at } 1500^{\circ} \mathrm{C} \\
\text { with } \mathrm{P}_{2} \mathrm{O}_{5}\end{array}$ & ${ }^{\circ} \mathrm{C}$ & -- & -- \\
\hline
\end{tabular}

In order to determine if phosphorus present in the iridium, rather than in the annealing atmosphere, will also enhance grain growth, we ran the following experiment. Sample OLMF-8-60 was annealed with $\mathrm{P}_{2} \mathrm{O}_{5}$ for $1 \mathrm{~h}$ at $1500^{\circ} \mathrm{C}$. The grain size was measured as 19 grains per thickness, compared to 25 to 28 per thickness typically observed for DOP-26. As shown in Table III-1, the grain boundaries contained high phosphorus concentrations. A piece of this specimen (OLMF-8-44B) was then annealed for an additional $18 \mathrm{~h}$ at $1500^{\circ} \mathrm{C}$ in vacuum in a clean graphite crucible. The grains grew enormously, to average 4.7 grai ss thickness. The grain growth was very nonuniform with some grains as large as two-thirds of the thickness of the specimen (see Fig. III-3). These results indicate that phosphorus in the grain boundaries of iridium will enhance grain growth significantly even in the absence of phosphorus in the atmosphere.

Since the $1 \mathrm{~h}$ at $1500^{\circ} \mathrm{C}$ treatment was successful in putting phosphorus in the grain boundaries, it makes it possible to control the grain size of phosphorusdoped specimens. To achieve a grain size of 412 grains/thickness, specimens were 


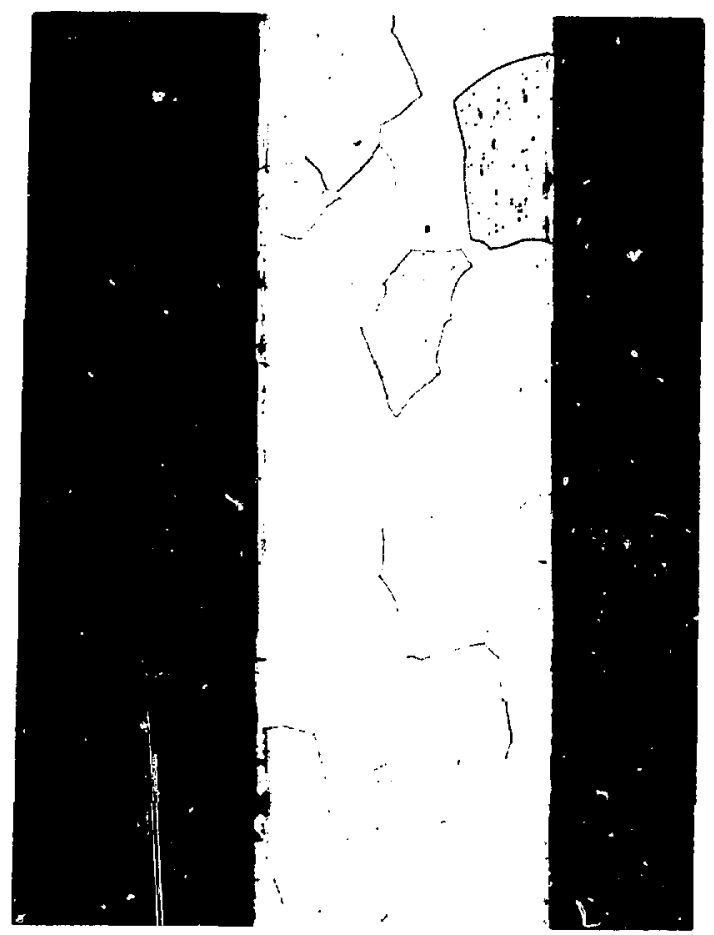

(a)

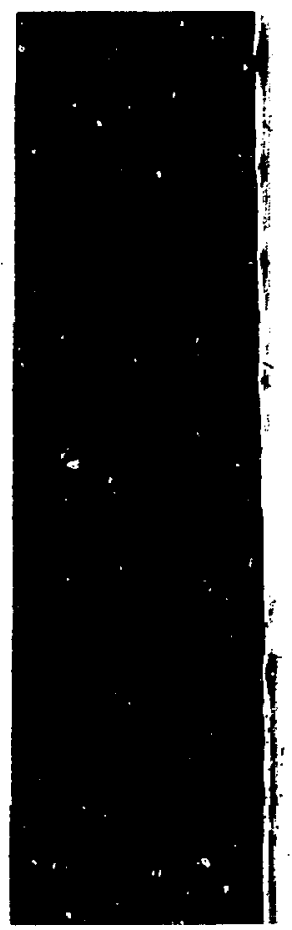

(b)

Fig. III-3.

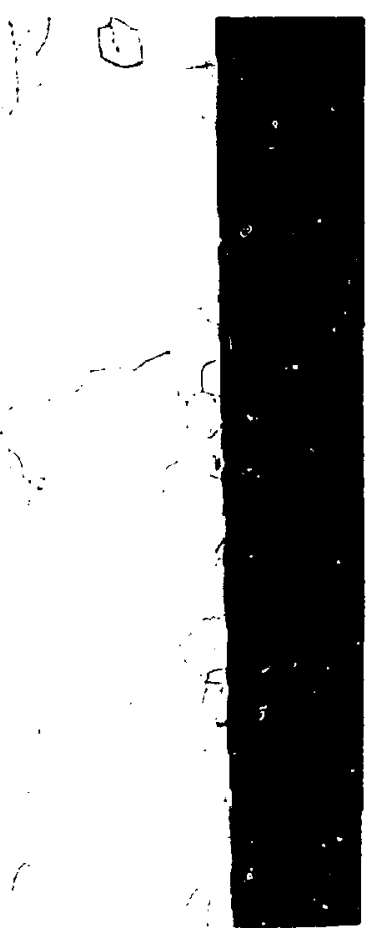

Metallographic cross sections of OLMF-8-44B annealed $1 \mathrm{~h}$ at $1500^{\circ} \mathrm{C}$ with $\mathrm{P}_{2} \mathrm{O}_{5}$ plus $18 \mathrm{~h}$ at $1500^{\circ} \mathrm{C}$ in vacuum. a) and b) represent cross sections from the same specimen.

arnealed at $1500^{\circ} \mathrm{C}$ for $18 \mathrm{~h}$ in vacuum followed by $: \mathrm{h}$ at $1500^{\circ} \mathrm{C}$ with $\mathrm{P}_{2} \mathrm{O}_{5}$. The resulting grain size was 12.6 grains/thickness (see Table III-1). We are currently examining this material by Auger Electron Spectroscopy to check the phosphorus levels at the grain boundaries. Four tensile specimens that received this treatment were sent to Oak Ridge National Laboratory (ORNL) for tensile impact testing. One small section was sent to Don David at Mound Facility (MF) for Auger studies. One disk for biaxial testing was also given the phosphorus-doping treatment.

3. Fuel Impurities. An attempt to detect phosphorus impurity in the plutonia spheres of assemblies on hand at LASL by gamma-ray spectroscopy has been carried out. The technique yields analytical data for aluminum and sodium in addition to phosphorus. The results obtained with FSAs MHFT-67 through -72 are summarized in Table III-2 along with available corresponding analyses from Savannah River (SR). The agreement between the analyses for sodium are quite good, but less so for aluminum, with the gamma-ray results showing lower concentrations than the emission spectrographic technique. The gamma-ray results indicate the phosphorus content to be very low. 
TABLE III-2

SUMMARY OF $\gamma$-RAY SPECTROCOPY

ANALYSIS OF PHOSPHORUS, ALUMINUM, AND SODIUM

IN MHW-FSAS

\begin{tabular}{|c|c|c|c|c|c|c|}
\hline & Pho & orus & Al & num & & \\
\hline & $\gamma$-ray & $S R^{*}$ & $\gamma-r a y$ & $S R$ & $y-r$ & SR \\
\hline MHFT -67 & $<25$ & - & -- & $>200$ & -- & 10 \\
\hline MHFT-68 & $<20$ & -- & 20 & 75 & 20 & $1 !$ \\
\hline MHFT-69 & $<20$ & -- & 29 & $>200$ & -- & 25 \\
\hline MHFT-70 & $<20$ & -- & 10 & 75 & 19 & 20 \\
\hline MHFT-71 & $<20$ & -- & 7 & 75 & 10 & 10 \\
\hline MHFT-72 & $<20$ & - & 24 & -- & -- & -- \\
\hline
\end{tabular}

₹SR anaTysis on feed powder from HB line. 